\title{
Effect of Autoclave Sterilisation on the Dimensional Stability and Tear Strength of Three Silicone Impression Materials
}

\author{
Brian J. Millar ${ }^{1 *}$, Sanjukta Deb ${ }^{2}$ \\ ${ }^{1}$ Restorative Dentistry, Department of Primary Dental Care, King's College London Dental Institute, London, UK \\ ${ }^{2}$ Department of Biomaterials, Biomimetics \& Biophotonics, King's College London Dental Institute, London, UK \\ Email: ${ }^{*}$ brian.millar@kcl.ac.uk
}

Received 10 October 2014; revised 26 November 2014; accepted 13 December 2014

Copyright (C) 2014 by authors and Scientific Research Publishing Inc.

This work is licensed under the Creative Commons Attribution International License (CC BY). http://creativecommons.org/licenses/by/4.0/

(c) (i) Open Access

\begin{abstract}
Objectives: There is a risk of spreading infectious material via non-sterile impressions. The aim of this study was to compare the effect of autoclave sterilisation on dimensional stability and tear strength of impression materials. Methods: Twenty-four specimens were produced using a standard ruled test block for each of three impression materials (Affinis, Aquasil and Speedex) to test dimensional stability. Thirty tear strips for each material were prepared for the tear test (ISO 34-1). Specimens were randomly allocated to 3 different groups (autoclaved, disinfected or untreated). A non-contact scanner was used to analyse dimensional change and a universal testing machine was used to determine tear strengths. Results: There were no significant differences in the test dimensions measured for any of the three impression materials following autoclave treatment compared to the disinfected or untreated control groups. The tear strengths were not adversely affected by autoclave sterilisation at $134^{\circ} \mathrm{C}$. Conclusion: These addition and condensation-cured silicone impression materials can be steam autoclaved without adverse effects on dimensional accuracy or tear strength.
\end{abstract}

\section{Keywords}

Impressions, Autoclaving, Sterilisation

\section{Introduction}

There is an increased awareness of the risks through cross-infection within dental practice and autoclave sterilisation is the preferred option to deal with non-disposable items, which have come into contact with the oral tis-

"Corresponding author.

How to cite this paper: Millar, B.J. and Deb, S. (2014) Effect of Autoclave Sterilisation on the Dimensional Stability and Tear Strength of Three Silicone Impression Materials. Open Journal of Stomatology, 4, 518-526.

http://dx.doi.org/10.4236/ojst.2014.412069 
sues. However, the current standard for dental impressions after removal from the mouth is disinfection despite studies [1] [2] showing disinfection does not remove potential contaminants. The important potential route of transmission of infective material from a patient to the dental laboratory and beyond via an impression is best dealt with by sterilisation of the impression at source soon after removal from the oral cavity.

It has been known for many years that saliva is a carrier for numerous pathogenic bacteria; $67 \%$ of impressions were found to carry such organisms as E. coli, Enterobacter cloacae and Klebsiella oxytoca, alongside many more [3]. A study carried out in Hong Kong found that only $48 \%$ of the dentists surveyed disinfected their impressions and only $74 \%$ rinsed their working impression after removal from the mouth [4]. A similar recent study in Ireland revealed that $18 \%$ of the dentists do not disinfect their impressions [5].

It has been documented that there is a lack of communication between dentists and laboratory personnel regarding disinfection techniques. In a questionnaire study of dental laboratories $44 \%$ of respondents stated that they were aware that impressions were disinfected [6]. Furthermore, 23\% of laboratory personnel were unaware of the disinfection procedure used and $47 \%$ were unaware of the length of time used.

Sterilisation refers to the total elimination of all micro-organisms and spores. Blair and Wassell [7] concluded that there was no universally recognised impression disinfection/sterilisation protocol. Although sterilisation is a preferred method of cross-infection control in the clinic, manufacturers have not investigated the sterilization of their impression materials. Manufacturer's instructions recommend disinfecting impression materials by using chemical solutions. However, Holtan [8] concluded that polyvinylsiloxane impression materials were able to tolerate the sterilisation procedure (ethylene oxide) and produce accurate casts. The most common method of sterilisation employed by hospitals and dental professionals is steam autoclaving. A survey by dentists in general practice [2] found that $50 \%$ of the dentists questioned would favour an impression material, which could be autoclaved.

Olin et al. [9] reported the use of ethylene oxide gas autoclaving of heavy and light bodied addition silicone impression material in custom autopolymerising acrylic resin trays. The results of this study showed that there were significant structural changes ( $>0.5 \%$ change) occurring post-autoclaving suggesting that this is due to the distortion of the trays themselves or their incapability to prevent expansion of the impression material. Another study showed that a polyvinylsiloxane (addition cure silicone) impression material could be autoclaved without any significant dimensional changes using stock metal trays, albeit, it should be viewed cautiously when sterilised at $132^{\circ} \mathrm{C}$ [8]. This was further supported with addition-cured silicone impressions autoclaved at $134^{\circ} \mathrm{C}$ producing less than $0.5 \%$ dimensional change [10]. Given that there is now evidence that impression materials can be autoclave-sterilised and that clinical practitioners prefer sterilisation in general, a suitable type of tray and adhesive is now available [11]; a range of materials needs to be evaluated.

The aim of the study was to investigate whether the dimensional stability and tear strengths of addition-cured and condensation-cured silicone impression materials are significantly altered following steam autoclaving. A comparison was made with identical samples disinfected by immersion disinfection, as well as a group where no treatment was carried out.

\section{Materials \& Methods}

\subsection{Impression Materials Used}

Silicone based impression materials were chosen for this study to reflect the materials routinely adopted by many practices. The impression materials tested in this study included two addition-cured elastomers, Affinis light body (Coltene) and Aquasil low viscosity (Dentsply) which have different chemical compositions and one condensation-cured elastomer, Speedex (Coltene). No polyether based impression material was used as they cannot be autoclaved as they are unable to withstand high temperatures. The impression specimens (additioncured silicones: Affinis and Aquasil) were produced using a static mixing gun with an auto-mixing tip, which ensured dispensing equal amounts of each of the components and also the amount dispensed could be kept constant. The condensation-cured silicone, Speedex was hand-mixed. Equal lengths of Speedex base and Activator (Coltene) was dispensed, mixed thoroughly and spread onto the test block.

\subsection{Specimens for Dimensional Testing}

Impression specimens (24 for each of the three test materials) were produced to record the dimensional stability 
by dispensing material onto a ruled test block as shown in Figure 1. The materials were allowed 5 minutes to set which is longer than the recommended set-times before removing from the template. All specimens were bagged and sealed for allocation into test groups.

\subsection{Specimens for Tear Strength Testing}

For tear strength analysis strips (30 for each of the three test materials) were prepared for the "trouser-method" test (in compliance of ISO 34-1). The tear strength tests involved using the "trouser-piece" method and calculating the mean for each group. Tear strength strips were produced using a standard mould (Figure 2). This mould was sandwiched between two sheets of glass to maintain a standard thickness of $1 \mathrm{~mm}$. Setting time was increased to 8 minutes before removing from the mould to ensure no distortion would occur. Following removal, the tear strength strips were trimmed and an incision was made in the centre (10 $\mathrm{mm}$ from either side) and was cut down to the middle $(45 \mathrm{~mm})$ in preparation for the "trouser-method" test (in compliance of ISO 34-1). Specimens were bagged and sealed for allocation into test groups.

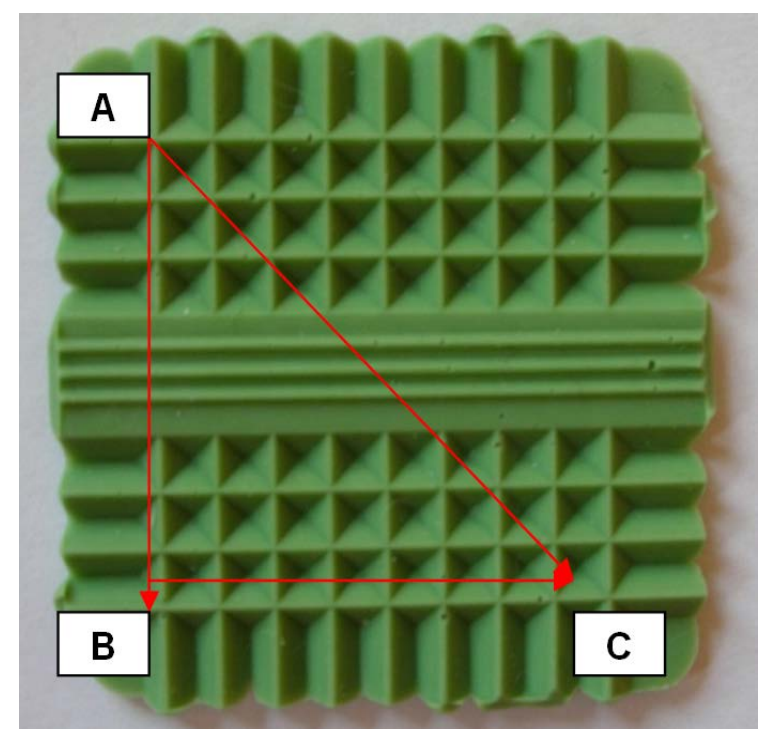

Figure 1. Three linear measurements were taken, one vertical, one horizontal and one diagonal. This was repeated for each specimen, for the 3 elastomeric impression materials.

Template used to produce Tear Strips for Tear strength analysis

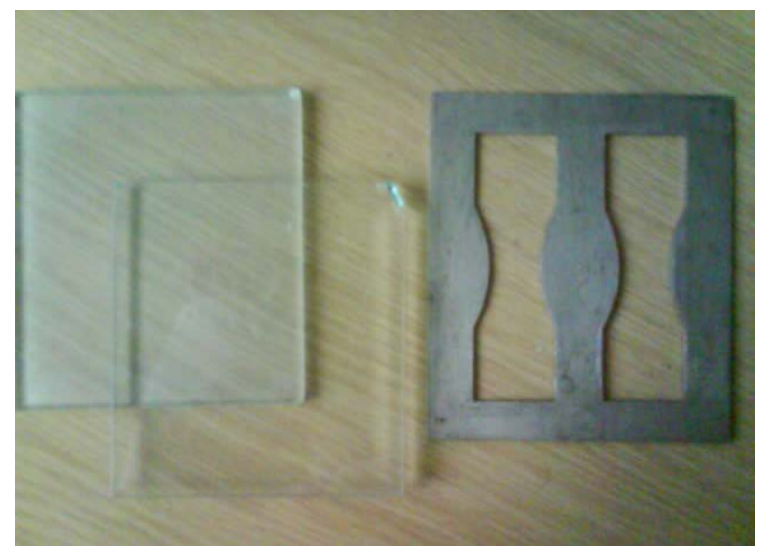

Figure 2. Two glass panels (left) and the template (right) used to produce the tear strength pieces. 


\subsection{Treatment Groups}

The specimens of these impression materials were randomly allocated to one of three experimental groups. These three groups enabled the comparison between treatments by autoclave sterilisation with two control groups. One control group were specimens, which were disinfected but not sterilised. In the autoclaved group the silicone impression specimens were sterilised by a standard cycle in the autoclave to reflect the autoclaving methods employed by dental practices to sterilise equipment. In the control group receiving the disinfection regime the specimens underwent an immersion disinfection procedure with the use of Perform ${ }^{\circledR}$-ID, which is the current technique employed in dental practices. Specimens were placed in Perform ${ }^{\circledR}$-ID (Shulke \& Mayr, UK, Ltd.), a chemical disinfectant which is an aldehyde-free solution containing potassium peroxomonosulphate, sodium benzoate and tartaric acid. Impression specimens were immersed in a solution of $2 \%$ Perform for 10 minutes, as recommended by the manufacturer, and then rinsed under the tap for 30 seconds. The second control group consisted of untreated specimens.

The silicone impressions specimens allocated to the autoclave treatment group were placed in individually sealed bags and underwent a standard autoclave cycle at $134^{\circ} \mathrm{C}$ for 30 minutes. This cycle includes the time required for steam autoclaving and drying time.

Following treatment all specimens were bagged and sealed for subsequent analysis within 24 hours. A 24 hour time period was used to simulate transportation from the dental surgery to the dental laboratory. This routine was chosen as most dental and hospital practices employ these methods for instrument sterilisation.

\subsection{Testing Dimensional Stability}

The specimens prepared for the dimensional stability tests were analysed using a non-contact scanner (Tai Caan Ltd.), scanned at 100 microns then stored in a CPU for analysis. Three linear measurements were taken from each specimen (A-B, B-C and A-C) as shown in Figure 1. This was repeated for all the specimens within a group and the mean was calculated.

\subsection{Tear Strength Test}

Tear strength strips were produced using a template (Figure 2). This template was sandwiched between two sheets of glass to maintain a standard width. Setting time was increased to 8 minutes before removing from the template. Following removal, the tear strength strips were trimmed and an incision was made in the centre (10 $\mathrm{mm}$ from either side) and was cut down to the middle $(45 \mathrm{~mm})$ in preparation for the "trouser-method" test (in compliance of ISO 34-1).

The tear strength tests involved using the "trouser-piece" method. This involved clamping the opposing "tongues" of the tear strip into the Instron (1995) machine, calibrated to move at $10 \mathrm{~mm}$ per minute. The clamps would move in opposite directions until a tear was initiated and maintained (Figure 3). The maximum force exerted to initiate a tear was measured electronically. The tear strength was calculated as the force required to initiate the tear divided by the specimen thickness (Tear strength = Force (Newton's)/Thickness (Millimetres)).

One-way analysis of variance (ANOVA) was used to test for statistically significant differences within the groups and also across the groups. A pairwise multiple comparison test (Tukey analysis) was also performed on some results to compare data between two sets of groups.

\section{Results}

\subsection{Dimensional Stability}

The dimensions of each of the specimens were measured as shown in Figure 1. A comparison of the mean values for each of the three test impression materials showed that there was no significant difference between the autoclaved, disinfected and control specimens in each case. No significant differences (using ANOVA and Tukey test) were observed across the three treatments for the dimensions A-B, B-C or A-C. Table 1 summarizes the mean and standard deviation values for each group of specimens and Figure 4 illustrates the comparisons between the three treatments for the three impression materials.

A comparison of the mean values for the three different test materials for each of the treatments was carried out. A pair wise multiple comparison (Tukey Test) showed a significant difference between the materials Affinis 
The Instron Machine Used to Determine Tear Strength Values
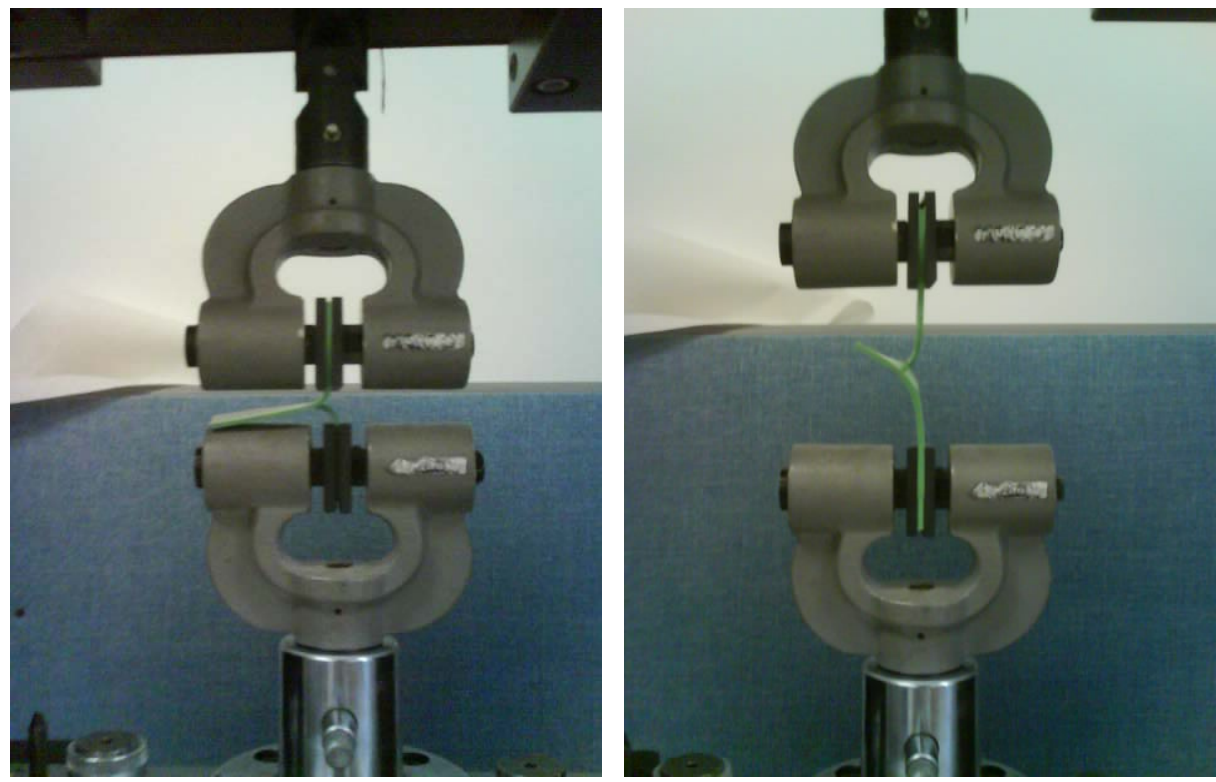

Figure 3. Specimen was clamped and pulled apart at a rate of $10 \mathrm{~mm} /$ minute until a tear was initiated and recorded electronically. The highest force recorded was then divided by the width to give a value in Newton's/mm.

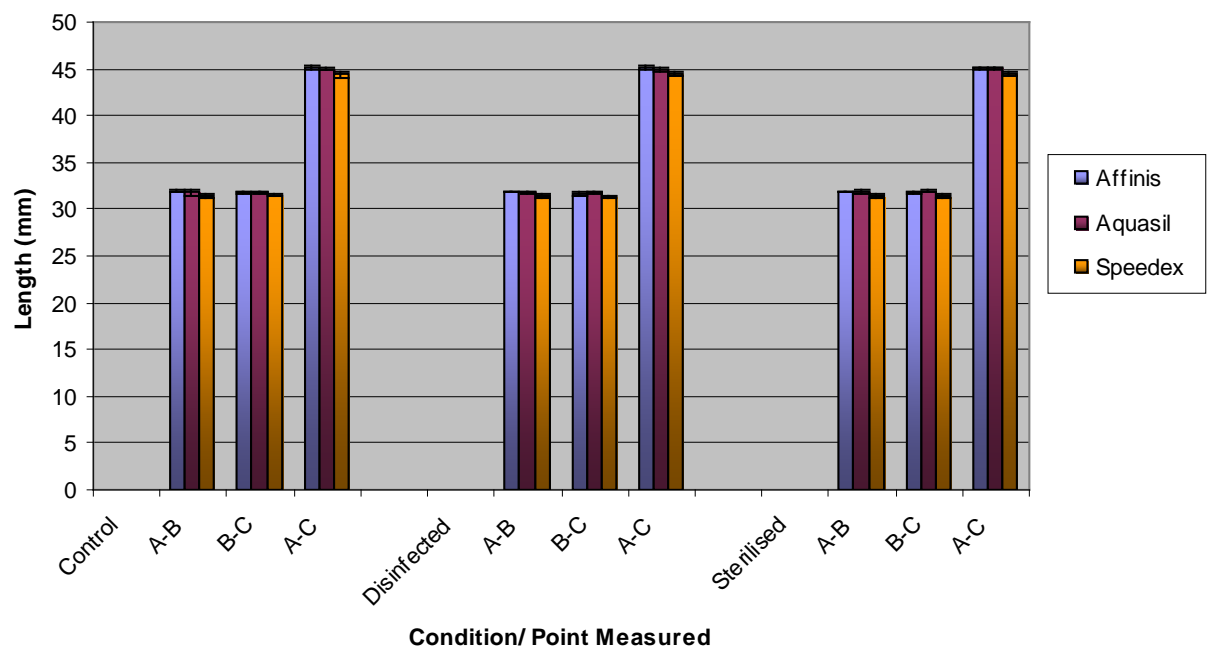

Figure 4. Mean dimensional stability values, $\mathrm{n}=8$. Control: no disinfection or sterilisation; Disinfected: immersed in Perform for 10 minutes; Sterilised: autoclaved at $134^{\circ} \mathrm{C}$.

and Speedex ( $\mathrm{p} \leq 0.001$ in all three treatment conditions (except control specimens for dimension B-C) and Aquasil and Speedex $(\mathrm{p} \leq 0.001-\mathrm{p}=0.008)$ ). However no significant difference was observed between Affinis and Aquasil across all the treatment conditions for each of the dimensions measured.

\subsection{Tear Strength}

The mean tear strength values for the three test materials in each of the treatment groups are shown in Table 2. A comparison of the mean tear strength values for the material Affinis showed that there was a significant difference between the autoclaved, disinfected and control specimens. Following disinfection and autoclaving the tear strength of the Affinis samples was significantly $(\mathrm{p}<0.001)$ greater than the control specimens whereas Aquasil showed no significant difference between the autoclaved, disinfected and control specimens. The tear 
Table 1. A comparison of dimensional stability values of 3 impression materials which have undergone disinfection, sterilisation or no treatment.

\begin{tabular}{ccccccc}
\hline & Affinis & SD & Aquasil & SD & Speedex & SD \\
\hline Control & & & & & & \\
A-B & 31.94 & 0.10 & 31.83 & 0.13 & 31.42 & 0.21 \\
B-C & 31.83 & 0.12 & 31.78 & 0.16 & 31.51 & 0.19 \\
A-C & 45.13 & 0.18 & 45.01 & 0.15 & 44.36 & 0.24 \\
Disinfected & & & & & & \\
A-B & 31.89 & 0.06 & 31.81 & 0.11 & 31.42 & 0.19 \\
B-C & 31.73 & 0.23 & 31.78 & 0.13 & 31.32 & 0.18 \\
A-C & 45.14 & 0.15 & 44.94 & 0.14 & 44.43 & 0.23 \\
Sterilised & & & & & & \\
A-B & 31.85 & 0.06 & 31.87 & 0.14 & 31.38 & 0.21 \\
B-C & 31.83 & 0.10 & 31.90 & 0.13 & 31.43 & 0.16 \\
A-C & 45.06 & 0.13 & 45.08 & 0.15 & 44.42 & 0.23 \\
\hline
\end{tabular}

Specimens were scanned by a non-contact scanner and dimensions A-B, B-C and A-C (see Figure 2) were determined for the three impression materials following the three treatments. There was no significant difference for each material according to treatment. However, there was a significant difference $(p<0.001)$ between Affinis and Speedex, and Aquasil and Speedex, within each treatment.

Table 2. A comparison of the tear strength values of the 3 silicone impression materials to disinfected, sterilized or untreated specimens.

\begin{tabular}{cccc}
\hline & Affinis LV & Aquasil LV & Speedex LV \\
\hline Control (Mean) & $0.38^{* / * *}$ & 0.83 & 0.41 \\
SD & 0.04 & 0.12 & 0.07 \\
Disinfected (Mean) & $0.46^{*}$ & 0.81 & $0.44^{* * *}$ \\
SD & 0.06 & 0.1 & 0.05 \\
Sterilised (Mean) & $0.54^{* *}$ & 0.71 & $0.34^{* * *}$ \\
SD & 0.02 & 0.1 & 0.04 \\
\hline
\end{tabular}

The tear strength of the three impression materials post disinfection and sterilisation. Values are an average, expressed in Newtons per millimetre $(\mathrm{N} / \mathrm{mm})$. $\mathrm{SD}=$ Standard Deviation, $\mathrm{n}=30$ for each group. Values sharing same * were significantly different.

strength following autoclaving was lower than the control group but only reached a significance level of $\mathrm{p}=$ 0.05. Similarly, Speedex showed no significant differences in the tear strength between the disinfected and control specimens $(\mathrm{p}=0.45)$. The autoclaved Speedex specimens had significantly lower tear strengths than the disinfected specimens $(\mathrm{p}=0.02)$.

Figure 5 illustrates the tear strength comparisons between the three treatments for the three impression materials. There were significant differences $(\mathrm{p}<0.001)$ observed for the tear strength when comparing the three materials in all treatment groups. For the control and disinfection groups, a Tukey test showed a significant difference between Affinis and Aquasil $(\mathrm{p}<0.001)$ and also for Aquasil and Speedex ( $\mathrm{p}<0.001)$. No significant difference was observed between Affinis and Speedex (control $p=0.704$ and disinfection $p=0.816$ ). However following autoclaving there was a significant difference between all the materials $(\mathrm{p}<0.001)$.

Comparing the treatment groups across all impression materials together for tear strength it was observed that there was a significant difference observed between the treatment groups $(\mathrm{p}=0.041)$. The Tukey test showed a 


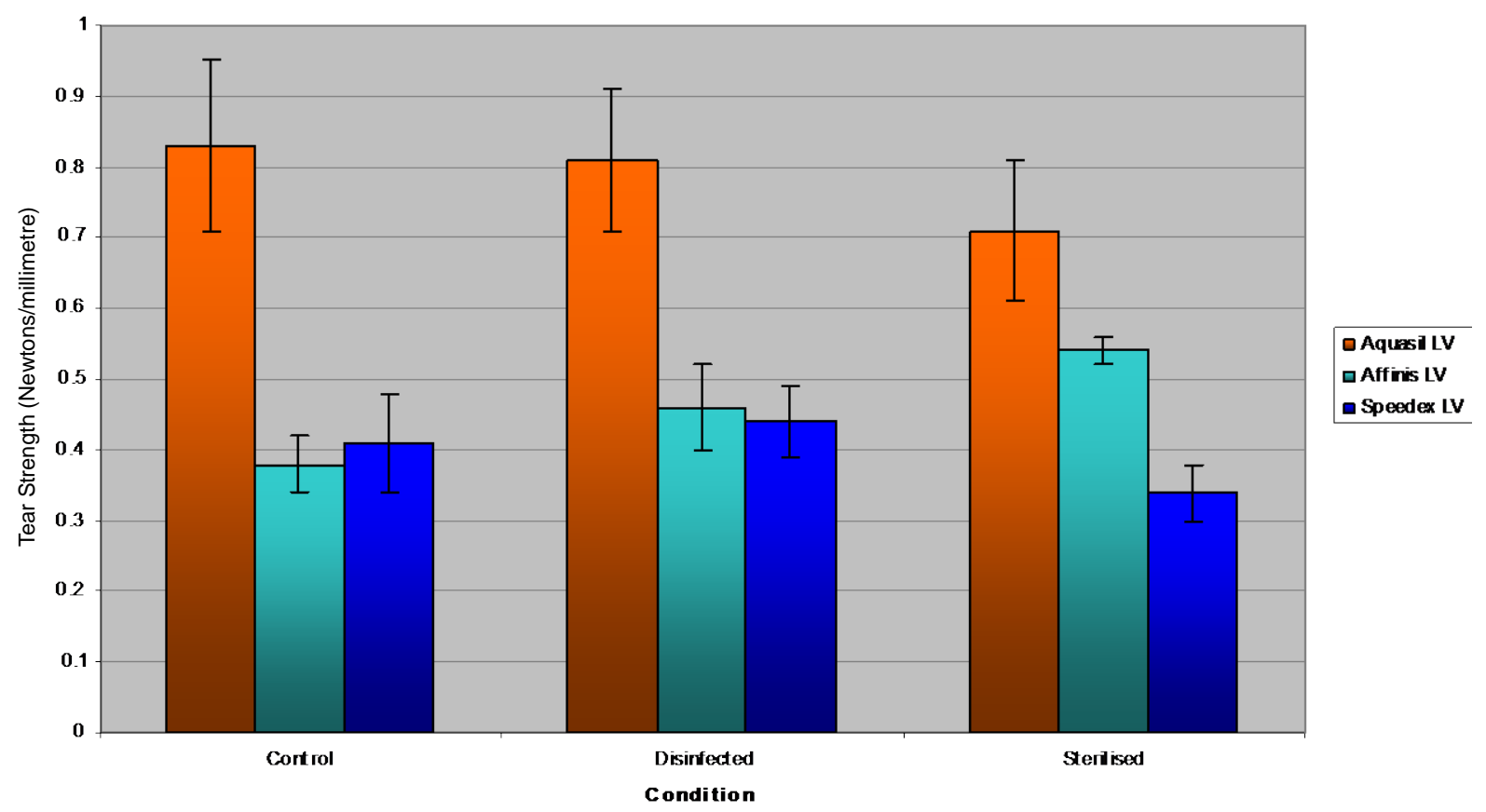

Figure 5. Tear strength values for three impression materials following control, disinfection by immersion into Perform-ID for 10 minutes or sterilisation by autoclaving at $134^{\circ} \mathrm{C}$.

significant difference existed between the control and sterilised group $(\mathrm{p}=0.047)$ but not between the control and disinfected group $(\mathrm{p}=0.909)$ nor between the disinfected and sterilised group $(\mathrm{p}=0.111)$. A significant difference $(\mathrm{p}=0.001)$ was observed between the three treatment groups for tear strength. A Tukey test showed a significant difference between the control and sterilised group $(\mathrm{p}=0.022)$ and between the disinfected and sterilised group ( $\mathrm{p}=0.001)$ but not between the control and disinfected group $(\mathrm{p}=0.449)$ when all impression materials were considered together.

\section{Discussion}

Silicone impression materials are considered to be suitable impression materials to use for fixed prostheses. They exhibit tolerance to heat and therefore addition cured silicones have been suggested to be one of the few materials that could tolerate steam autoclaving [8]-[10]. Studies have also shown the ability for addition cured silicone to remain dimensionally stable through disinfection procedures [12] [13]. They have also been shown to produce statistically significant more accurate casts than alginate materials [14].

The dimensional accuracy was measured using specimens as shown in Figure 1 and linear dimensions were recorded with three points of reference. The distances were measured with a non-contacting laser scanner, thus preventing any distortion during measurement.

The greater shrinkage observed in control specimens for Aquasil over Affinis, both setting by an addition reaction, may be due to the increased cross-linking taking place due to the presence of an additional cross-linking agent (quadrafunctional monomer) to increase the tear strength. Speedex sets by a condensation reaction hence the greater shrinkage observed.

A comparison of dimensional accuracy following autoclave treatment showed that there was no significant change when compared to conventional disinfection or when compared to untreated specimens. This was the case for all the three test materials and indicates that the vacuum cycle or heat does not adversely affect the dimensional accuracy of the cured impression material.

Speedex is a condensation-cured silicone therefore the differences observed between this material and the two addition-cured materials may be due to the different setting reaction which decreases the overall dimensional accuracy. These differences between the materials were not due to the sterilisation procedure, as differences were noted across all the conditions for each distance measured. Therefore, sterilisation and disinfection did not 
cause significant changes between the impression materials. Affinis and Aquasil are addition cured impression materials, which undergo minimal shrinkage post setting and are dimensionally stable.

Ahmad [13] reported that immersion disinfection with Perform-ID had no effect on addition cured silicones and showed that Affinis can maintain dimensional stability following immersion disinfection for 10 minutes in Perform-ID. There are many studies which have determined that disinfection by immersion alters dimensional accuracy on silicone materials and polyether materials [15]. Mandikos [16] reported that lower viscosity impression materials displayed greatest changes due to a lower filler content but this could also be due to differences in the molecular weight of the polysiloxane present. However, large volumes of filler results in decreased elasticity and fluidity, therefore decreasing accuracy. In this study low viscosity impression materials were used for the three impression materials and the comparison on dimensional stability indicated that steam autoclaving did not have an adverse effect on the dimensional stability and thus accuracy of the impression will be maintained.

Following autoclaving differences in tear strengths were observed between all materials. Although they would not be clinically relevant the changes may be relevant in the dental laboratory when pouring casts. The tear strength for Affinis increased, whereas the tear strength for Aquasil and Speedex decreased, hence creating a significant difference when comparing the results in this study.

This study found a significant difference between the tear strengths of the impression materials in all test groups. As expected, Aquasil has a high tear strength values due to the presence of the quadrafunctional vinyl polysiloxane, which increases the cross-linking of this material. Although Aquasil and Affinis are both addition-cured silicones, both impression materials give significantly different responses to tear testing. For this reason, it is not suitable to compare different bands within a single generic group, as also shown by Martin et al. [17].

The disinfected and sterilised group of Affinis exhibited significantly greater tear strengths than the control Affinis specimens. The sterilised group of Affinis showed the highest tear strength with an increase post sterilisation. As the exact chemical composition is not known, it can be speculated that the presence of crosslinking agents cross linked the matrix further on steam sterilisation and the tear strength increased. The additional crosslinking claimed for Aquasil may result in these higher tear strength values observed overall. Although a significant difference was observed for tear strength for the combined impression types between the control specimens and sterilised specimens ( $p=0.047)$, the difference is considered to be clinically acceptable.

With the exception of the control group, Speedex specimens exhibited lower tear strength values compared to the addition silicones, Affinis and Aquasil, in the disinfected and sterilised groups. This may be attributed to the contraction during cross-linking and the liberation of ethyl alcohol, which alters the tear strength. Also, hydrophilic silicones may absorb water during the immersion disinfection procedure. This will vary between materials according to the amount of intrinsic surfactant present but is has been shown that tear strength is directly related to wettability due to the level of surfactant incorporated in the material [18].

A recent study showed that $50 \%$ of dentists stated that they would prefer autoclavable impression materials [4]. The present study shows that the 2 addition-cured silicones, Affinis and Aquasil and condensation cured silicone, Speedex, can withstand the normal cycle of sterilisation by steam autoclaving. Furthermore, manufacturers could test their own brands and develop a colour-changing material, which indicates successful sterilisation by autoclaving. Manufacturers would also be required to develop trays that can withstand autoclaving [11].

Dental personnel should strive for sterilisation where possible. Sofou [19] found that the percentage of impressions which were claimed to have been disinfected which exhibited bacterial growth was $63 \%$ similar to the bacterial count on non-disinfected impressions. These results indicate that some of the methods employed by dental practices are insufficient to remove all bacterial species from the impressions. A recent survey [5] revealed that $18 \%$ dentists do not disinfect impressions prior to sending to a laboratory. Furthermore, the standard disinfection solutions may not be successful in treating the emergence of new infective species. Further development and clinical testing of autoclavable impression materials is of future interest.

\section{Conclusion}

Infection control has become a major focus for dental personnel. The clinical implications of this laboratory study are that dental impressions produced from addition-cured or condensation-cured silicone can be sterilised by steam autoclaving, when compared with disinfection with Perform-ID and untreated specimens, without producing significant dimensional changes or clinically relevant changes in tear strength. 


\section{Acknowledgements}

Dr. Treana Wu grateful assistance in carrying out the study is recognised.

\section{References}

[1] Egusa, H., Watamoto, T., Matsumoto, T., Abe, K., Kobayashi, M., Akashi, Y. and Yatani, H. (2008) Clinical Evaluation of the Efficacy of Removing Microorganisms to Disinfect Patient-Derived Dental Impressions. International Journal of Prosthodontics, 21, 531-538.

[2] Giammanco, G.M., Melilli, D., Rallo, A., Pecorella, S., Mammina, C. and Pizzo, G. (2009) Resistance to Disinfection of a Polymicrobial Association Contaminating the Surface of Elastomeric Dental Impressions. New Microbiologica, 32, 167-172.

[3] Powell, G.L., Runnells, R.D., Saxon, B.A. and Whisenant, B.K. (1990) The Presence and Identification of Organisms Transmitted to Dental Laboratories. Journal of Prosthetic Dentistry, 64, 235-237. http://dx.doi.org/10.1016/0022-3913(90)90185-F

[4] Pang, S.K. and Millar, B.J. (2006) Cross Infection Control of Impressions: A Questionnaire Survey of Practice among Private Dentists in Hong Kong. Hong Kong Dental Journal, 3, 89-93.

[5] Rath, C., Sharpling, W.D. and Millar, B.J. (2010) Review of the Provision of Crowns by Dentists in Ireland. Journal of the Irish Dental Association, 56, 178-185.

[6] Kugel, G., Perry, R.D., Ferrari, M. and Lalicata, P. (2000) Disinfection and Communication Practices: A Survey of U.C Dental Laboratories. Journal of the American Dental Association, 131, 786-792. http://dx.doi.org/10.14219/jada.archive.2000.0278

[7] Blair, F.M. and Wassell, R.W. (1996) A Survey of the Methods of Disinfection of Dental Impressions Used in Dental Hospitals in the United Kingdom. British Dental Journal, 180, 369-375. http://dx.doi.org/10.1038/sj.bdj.4809092

[8] Holtan, J.R., Olin, P.S. and Rudney, J.D. (1991) Dimensional Stability of a Polyvinylsiloxane Impression Material Following Ethylene Oxide and Steam Autoclave Sterilisation. Journal of Prosthetic Dentistry, 65, 519-525. http://dx.doi.org/10.1016/0022-3913(91)90292-5

[9] Olin, P.S., Holtan, J.R., Breitbach, R.S. and Rudney, J.D. (1994) The Effects of Sterilization on Addition Silicone Impressions in Custom and Stock Metal Trays. Journal of Prosthetic Dentistry, 71, 625-630. http://dx.doi.org/10.1016/0022-3913(94)90449-9

[10] Millar, B.J. (1999) Dimensional Stability of Additional Cured Silicone Impressions Following Autoclave Sterilization. Journal of Dental Research, 78, 297.

[11] Deb, S., Etemad-Shahidi, S. and Millar, B.J. (2014) Dimensional Stability of Autoclave Sterilised Addition Cured Impressions and Trays. European Journal of Prosthodontics and Restorative Dentistry, 22, 35-42.

[12] Mathyas, J., Dao, N., Caputo, A.A. and Lucatorto, F.M. (1990) Effects of Disinfectants on Dimensional Accuracy of Impression Materials. Journal of Prosthetic Dentistry, 64, 25-31. http://dx.doi.org/10.1016/0022-3913(90)90148-6

[13] Ahmad, S., Tredwin, C.J., Nesbit, M. and Moles, D.R. (2007) Effect of Immersion Disinfection with Perform-ID on Alginate, an Alginate Alternative, an Addition-Cured Silicone and Resultant Type III Gypsum Casts. British Dental Journal, 202, 36-37.

[14] Bock, J.J., Fuhrmann, R.A. and Setz, J. (2008) The Influence of Different Disinfectants on Primary Impression Materials. Quintessence International, 39, 93-98.

[15] Melilli, D., Rallo, A., Cassaro, A. and Pizzo, G.I. (2008) The Effect of Immersion Disinfection Procedures on Dimensional Stability of Two Elastomeric Impression Materials. Journal of Oral Science, 50, 441-446. http://dx.doi.org/10.2334/josnusd.50.441

[16] Mandikos, M.N. (1998) Polyvinyl Siloxane Impression Materials: An Update on Clinical Use. Australian Dental Journal, 43, 428-434. http://dx.doi.org/10.1111/j.1834-7819.1998.tb00204.x

[17] Martin, N., Martin, M.V. and Jedynakiewicz, N. (2007) The Dimensional Stability of Dental Impression Materials Following Immersion in Disinfecting Solutions. Dental Materials, 23, 760-768. http://dx.doi.org/10.1016/j.dental.2007.01.004

[18] Millar, B.J., Wood, D.J., Bubb, N.L. and Gabrielson, L. (1995) Tear Strength of Hydrophilic and Hydrophobic Polyvinylsiloxane Materials. Journal of Dental Research, 74, 881.

[19] Sofou, A., Larsen, T., Fiehn, N.E. and Owall, B. (2002) Contamination Level of Alginate Impressions Arriving at a Dental Laboratory. Clinical Oral Investigations, 6, 161-165. 
Scientific Research Publishing (SCIRP) is one of the largest Open Access journal publishers. It is currently publishing more than 200 open access, online, peer-reviewed journals covering a wide range of academic disciplines. SCIRP serves the worldwide academic communities and contributes to the progress and application of science with its publication.

Other selected journals from SCIRP are listed as below. Submit your manuscript to us via either submit@scirp.org or Online Submission Portal.
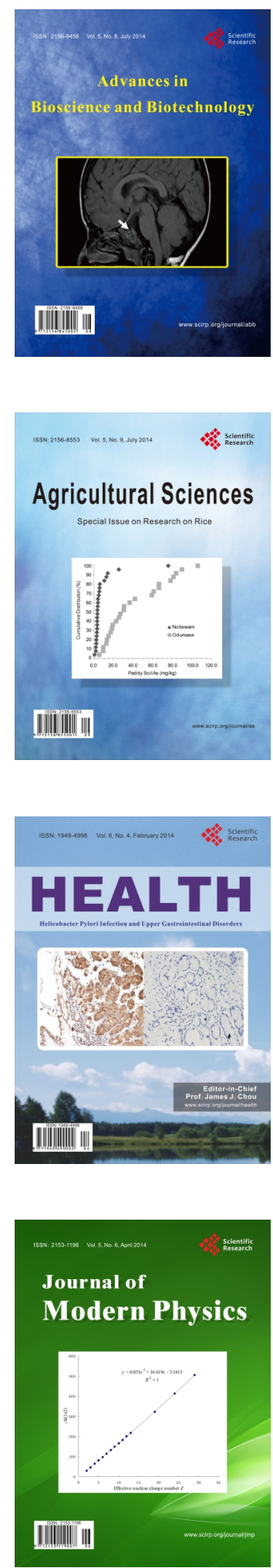
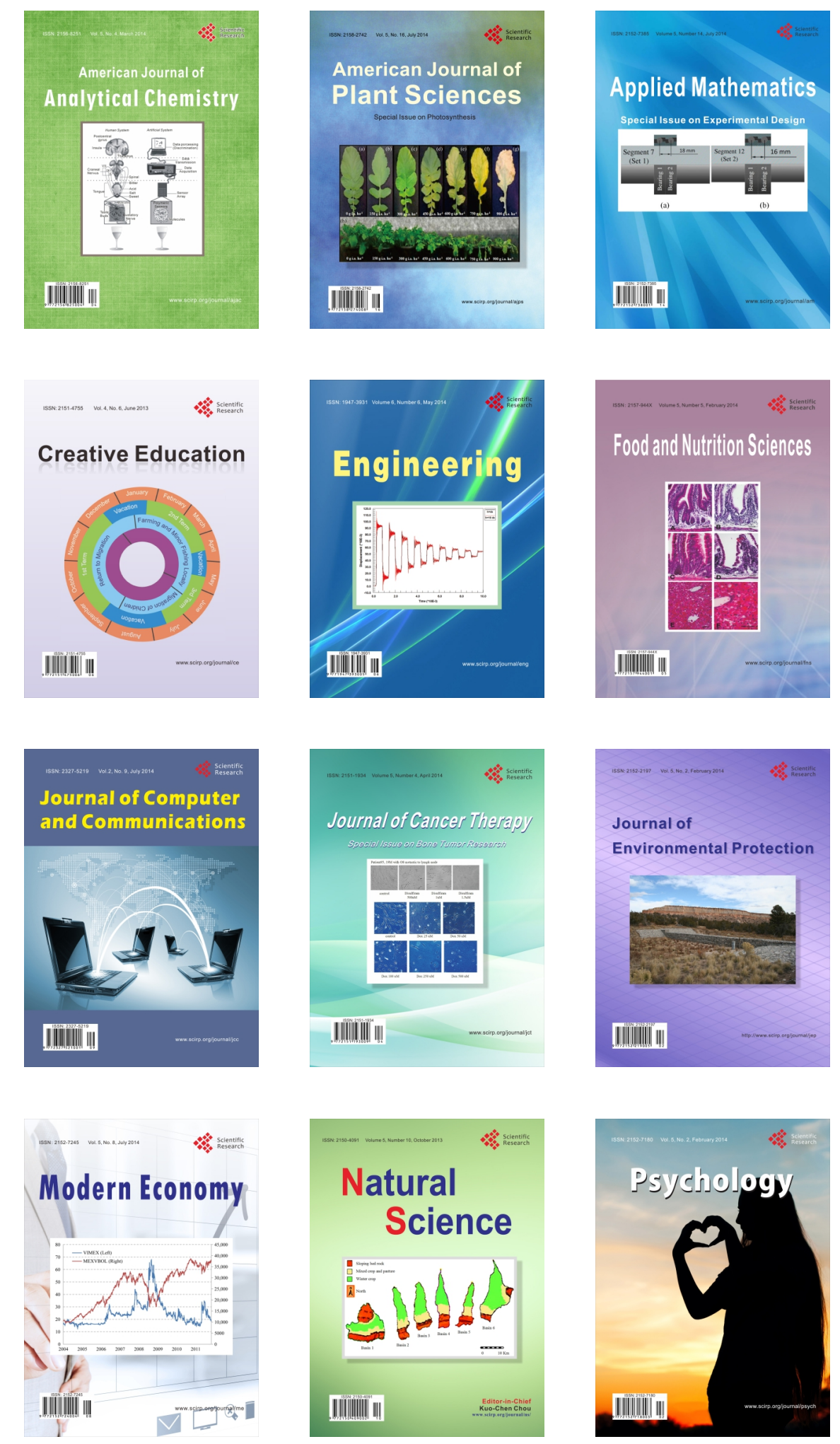